\title{
Türkçe gel- ve git- Fiillerinin Anlamı
}

\section{Meaning of Turkish Verbs gel- and git-}

\author{
Özen Yaylagül Üstünel \\ Prof. Dr., Ondokuz Mayıs Üniversitesi \\ Fen Edebiyat Fakültesi, Türk Dili ve Edebiyatı Bölümü, Samsun/Türkiye \\ e-posta ozeny@omu.edu.tr, ozyaylagul@yahoo.com \\ orcid 0000-0001-5632-6999 \\ doi $\quad 10.54316 /$ dilarastirmalari.1001864
}

Atıf

Citation

Yaylagül Üstünel, Özen (2021). Türkçe gel- ve gitFiillerinin Anlamı.

Dil Araştırmaları, 29: 31-41.

$\begin{aligned} & \text { Başvuru } \\ & \text { Submitted } \\ & 30.09 .2021\end{aligned}$
Revizyon
Revised
02.11 .2021
Kabul
Accepted
05.11 .2021
Çevrimiçi Yayın
Published Online
30.11.2021

Öz

$\mathrm{Bu}$ çalışma ile Türkçedeki gel- ve git- fiilleri edimbilimsel açıdan çözümlenmeye çalışılmıştır. Gel- ve git- fiilleri temel anlamları dikkate alındığında karşıt anlamlı gösterimsel hareket fiilleri olup ikincil anlamları sanılandan daha karmaşıktır. Gel- fiili temel anlamıyla hedefe yönelik bir fiil olup hareketin hedefi bilinen bir yerdir. Konuşmacı ve muhatabın konumundan bağımsız olarak gel-fiili genellikle git-fiilinden daha çok tercih edilir; kimi zaman gel-fiili git-fiili yerine kullanılabilir. Bununla birlikte her durumda $g e l$ - fiilinin git- fiili yerine kullanılamadığ da açıktır. gel- fiili ( <kel-) Türkçenin en eski yazılı belgeleri olan Türk runik harfli metinlerden itibaren yaygın bir kullanım alanına sahiptir. Türk runik harfli metinlerde git- fiili tespit edilememiştir. Söz konusu metinlerde 'gitmek, varmak' anlamına gelen sözcük bar- sözcügüdür. bar- fiili bugün daha çok 'ulaşmak' anlamıyla kullanılmaktadır. git(<két-) fiili ile eski Uygur sahası metinlerinden itibaren karşılaşılmaktadır. Çocuk dil edinimi sürecinde de gel- fiilinin edinimi git- fiilinden daha erken gerçekleşmektedir. Bu çalışmada gel- ve gitfiillerinin eşdizimliliğe bağlı olarak ortaya çıkan anlamları, kullanımları, uygulamaları da ele alınmış; bu amaçla TUD veri tabanı kullanılmıştır. Sonuç olarak gel- fiilinin eşdizimlilerinin sayısının çok daha fazla olduğu tespit edilmiştir.

Anahtar Kelimeler: Türkçe gösterimsel fiiller, edimbilimsel anlam, yönlü karşıtlıklar, eşdizimliler

\section{ABSTRACT}

This paper proposes alternative pragmatic analyses for Turkish verbs gel'to come' and git- 'to go'. When the central meanings of the verbs gel'to come' and git- 'to go' are taken into account, they are antonyms of deictic motion verbs and their connotative meanings are more complex than often assumed. In terms of central meaning of the verb gel- 'to come' is goal-oriented which goal of the motion is a known place. Regardless of the speaker's and the addressee's locations, come is often 
preferred over go but not ever. Verb gel- $(<\mathrm{kel}$-) has been widely used since the earliest written texts. The verb git- 'to go' could not be detected in Turkish runic texts. In the texts in question meaning 'to go' verb is bar-. Literally meaning of the verb bar-is 'to arrive' in Turkish today. The verb git- (<két-) can be used since the old Uigur texts. In Turkish, the verb gel- 'to come' is acquired before the verb git- 'to go' in the process of child language acquisition. In the study, it is aimed to examine the definitions, uses, applications and collocations of the verb gel- 'to come' and the verb git- 'to go'. For this purpose, the TUD database was used. As a result, it has been determined that the number of collocations of the verb gel- is much higher.

Keywords: Turkish deictic verbs, pragmatic meaning, directional opposites, collocations

\section{Giriş}

gel- ve git-fiilleri dünya dillerinde kullanım sıklığı yüksek temel fiiller arasındadır. $\mathrm{Bu}$ fiiller, fiillerin aynı formal alt sınıfina aittir. $\mathrm{Bu}$ sınıf hareket fiilleri olarak adlandırılır.

Parlak (2016, Shvedova 1970'den), Rusça hareket fiillerinin aynı kökten gelen ve iki üyeli ilişki grubu oluşturan, iki üyeli gruplardaki üyeler arasında uzunluk-kısalık ve tek yönlülük-çift yönlülük gibi anlamsal açılardan farklılık bulunan, yer değişimini niteleyen fiiller olarak tanımlandığını belirtir.

Bütün diller hareket fiilleri sınıfina sahiptir ve dillerde gel- ve git- eylemlerini karşılayacak fiiller bulunur. Bu eylemleri karşılayan sözcükler diğer dillerde olduğu gibi Türkçede de dilde en önce edinilen fiillerdendir. Öncül (2020) Türkçenin edinimiyle ilgili tez çalışmasında çocukların gel-fiilini 15. ayda, git- fiilini ise 16. ayda edindiğini tespit etmiştir.

Gel- ve git- fiilleri dinleyiciye cümle içinde sözlüksel anlamlarından daha fazla bilgi verir. Gel- ve git- fiilleri gösterimsel (deictic) fiillerdir (Wilkins and Hill 2000) ve bağlama bağlı olarak izah edilebilir. Bu nedenle bu çalışmada edimbilimsel yöntem kullanılarak gel- ve git- fiillerinin anlamları ele alınmış; gel-ve git-fiillerinin temel anlamı nedir? Gel- ve git-fiillerinin ifade ettiği gösterimsel (deictic) bilgi nerede ve nasıl kodlanır? gibi sorulara yanıt aranmıştır.

Edimbilim, bağlamsal anlama önem verir. Bağlam; yer, zaman, konuşmacı ve dinleyici arasındaki sosyal ilişkiler, daha geniş söylem bağlamı, dinleyici ve konuşmacının konuşma geçmişi, yardımcı metin/ler, paylaşılan genel kültürel art alan bilgisi gibi unsurları ihtiva edecek şekilde yapılanır. Konuşmacı ve dinleyici iletişim sürecinde üç aşama atlatır: anlambilimsel girdi-edimbilimsel yorumlamaanlambilimsel çıtı. Anlambilimsel girdi aşamasında tanınan göstergelerle ilgili depolanmış iletişim bilgisi dikkate alınır. Anlambilimsel çıktı aşamasında ise özel bağlamlarda ifadelerin son yorumları olarak türetilen bilgi dikkate alınır. Yorum için gösterim bağlamına da ihtiyaç duyan edimbilimsel bakış açısıyla gösterimsel ifadelerin (deictic expressions) ele alınması önemlidir.

$\mathrm{Bu}$ çalışmada kullanılan veri büyük ölçüde TUD veri tabanının taranmasıyla elde edilmiştir. 


\section{Bulgular}

Gel- fiili Türkçenin en eski yazılı belgeleri olan Orhun Yazıtları'nda kel- şeklinde tespit edilebilmiştir (BK D17). Buna karşılık két- fiili ancak eski Uygur sahası metinlerinden itibaren tanıklanabilmektedir. Türk runik harfli metinlerde két- fiili yerine bar- fiili (>TüT. var-) 'varmak, gitmek, ulaşmak' anlamlarıyla sıklıkla kullanılmıştır (Orkun 1994: 769; Tekin 2015: 50).

Clauson (1972: 701), bar- fiilinin két- fiilinin eş anlamlısı olduğunu belirtir "két(g-) 'to go', usually specifically 'to go away'; more or less syn. w. bar-". két- fiili 'gitmek' anlamı yanında 'gözden kaybolmak; hastalık / ağrı / acı kaybolmak' anlamını da taşır ve bu yönüyle bar-fiilinin yakın eş anlamlısı olarak görülebilir. két- ( < ké:tGülensoy 2018: 372) Eski Uygur Türkçesi Sözlüğü'nde kit- şeklinde 'gitmek, zail olmak' (Caferoğlu 1968: 113) anlamında verilmiştir. DLT'de ket- şeklinde 'gitmek, çekilmek' anlamında (yiparlıg käsürgüdin yipar ketsä yìdi kalır "When the musk goes from its bag its fragrance does not depart [lit. İs left behind]." (Dankoff and Kelly 1985 II: 173) yani 'İçinde amber olan kaptan amber gitse kokusu kalır') tespit edilmiştir. Şinasi Tekin, Willy Bang gibi Türkologlar etimolojik çalışmalarında Türkçe kelime köklerini tek bir ünlü veya ünsüz+ünlü yapısına kadar indirmeye çalışır. Buna göre kelve két- fiilleri için varsayımsal bir *kE- kökü tasarlanabilir. Söz konusu fiillerin yönelim farkı, fiilden fiil yapan ve fiil çatısını da belirleyici olan -l- ve -t- ekleriyle sağlanmıştır, denebilir.

Gel- ve git- fiilleri yönle ilgili karşıt anlamlı sözcüklerdir. Gel-fiilinin olumsuzu olan gelme- ve git- fiilinin olumsuzu olan gitme- fiillerinde yönlü bir karşıtlık söz konusu değildir. Dilbilgisel karşıt anlamlı sözcükler olarak değerlendirilebilecek bu fiillere eklenmiş olan -mA- olumsuzluk eki aynı zamanda gel-ve git- hareket fiillerini durgun fiiller haline sokar ve fiillerin kılınış özelliklerini değiştirir. Jackendoff (1987) fiilleri; GITME fiilleri (GO verbs), OLMA fiilleri (BE verbs) ve KALMA fiilleri (STAY verbs) olarak sınıflandırmıştır. Buna göre git- ve gel- sözcükleri temel anlamlarıyla GITME fiilleri, gitme- ve gelme- sözcükleri ise KALMA fiilleri arasında yer alan eylemleri karşılayan fiillerdir. Uzamsal pozisyon, iyelik ve yükleme anlam alanları içinde gel-ve git-fiilleri uzamsal pozisyonla ilgili fiillerdir (Steen 1996).

Gel-, git- fiilleri gösterimsel bilgiyi kodlar. Gel- fiili, git- fiiline göre daha gösterimsel bir fiildir. Gel-fiilinin git-fiilinden farkı hedef-yönlü olmasıdır. Genellikle yön, konuşan kişinin bulunduğu yere doğrudur ama zaman zaman bu yön değişebilir. Git- fiili gösterimsel (deictic) merkezden uzaklaşan bir eyleme işaret eder, 'Birisi konuşmacının şu anda bulunmadığı bir yere doğru hareket etti.’ anlamı verilebilir.

1) Ayşe bugün bana gelecek.

2) Ayşe bugün sana gelecek.

3) Şükran da dört-beş saat uyuyup gelmek üzere gidiyor.

4) Türkiye'ye bu yıl gelen turist saylsında artış oldu.

Birinci cümlede Ayşe'nin konuşmacının bulunduğu yere doğru, 2. cümlede ise dinleyicinin olduğu yere doğru hareketi söz konusudur ve her iki cümlede de gel-fiili kullanılmıştır. 3. cümlede gel- konuşmacının bulunduğu yere doğru, git- ise tam tersi 
bir yöne doğru hareketi gösterir. 4. cümlede ise eylemin konuşmaciya doğru olma zorunluluğu yoktur. Fakat hareketin hedefi bilinen bir yerdir. Hareketin başlangıç / çıkış noktası ise belirsizdir. Türkiye bu bağlamda öykünün konusudur ve bir gösterimsel merkez olarak iş görür.

Konuşmacı varış zamanında (gönderim zamanı 'reference time' olarak da adlandırılır) varış yerinde olduğunda gel- fiilinin kullanılması git- fiilinden daha uygundur. Konuşmacı konuşma zamanında varış yerindeyse gel- fiili tercih edilir. Ben biriyle konuşuyorken okuldaysam Ayşe yarın okula geliyor, derim. Ben yarın okulda olmayacak olsam da konuşma anında okulda olduğum için böyle bir cümle kurabilirim. Hareket konuşma anında konuşmacının bulunduğu yere doğrudur. Farklı gösterimsel (deictic) şartlara bağlı olarak gel- fiilinin anlamı değişebilir.

Gösterimsel ifadeler iletişim bağlamının katılımcıları veya bağlamla ilgili yer, zaman gibi belli detayları ortaya koymayı gerekli k1lar. Gel- ve git- gibi hareket fiillerinde bir yer değişikliği söz konusu olup gel- ve git- fiilleri genellikle konuşmaciya doğru ve konuşmacıdan ayrılan yöne doğru hareketi ifade eden fiiller olmakla birlikte bağlama göre bu durum değişebilmektedir. Gathercole (1977) gel- ve git- fiillerini Japonca, Türkçe, İspanyolca ve İngilizce'de karşıllaştırmalı olarak ele almış ve gel- fiilinin 'konuşmaciya doğru hareket', git- fiilinin ise 'konuşmaciya doğru olmayan hareket' ifade ettiğini belirtmiştir. Buna karş1lık Goddard (1997: 158) gelfiilinin anlamının basitçe 'konuşmacıya doğru hareket'e indirgenemeyeceğini belirtir. Aynı şekilde git- fiili için de konuşmacının dayanak noktası olduğu söylenemez. Ali, Ankara'dan İstanbul'a gitti cümlesini kurması için konuşmacının Ankara'da bulunma zorunluluğu yoktur. Gel- fiilinin yönelimi konuşma anında konuşmacının bulunduğu yer olmak zorunda değildir. Kuşkusuz sen o eve gelmek zorunda değildin cümlesinde konuşma anında konuşmacıya doğru bir hareketin söz konusu olmadığı hareketin hedef noktası olan $e v$ den önce gelen $o$ sıfatından anlaşılmaktadır. Konuşmacının yaşadığ 1 yer dışında bir yerde konuşmacının dinleyiciye Benim yaşadı̆ğm yere gelmek ister misiniz? Demesi durumunda gel- fiilinin hedefi konuşmacının da dinleyicinin de konuşma anında bulunmadığı bir yerdir. Soru cümlelerinde de gel- fiilinin yönelimi konuşmaciya doğru olmak zorunda değildir. Söz gelişi Ankara'daki Ayşe, İstanbul'daki Ali'ye Annen geldi mi? Diye sorabilir ve böyle bir cümlede gel-fiilinin yönelimi konuşmacıya doğru değil, dinleyiciye doğrudur. Burada konuşmacının kendini dinleyici yerine koyması veya dinleyici bakış açısıyla olaya bakması söz konusudur.

Siyasette gelmek kadar gitmek de vardir cümlesinde gel- ve git-fiillerinin hedef noktası belli bir yer değil, belli bir konum, iktidardır. Yaşlı bir kültürden gelmek harika bir duygu cümlesinde ise kaynak herhangi bir yer değil, soyut bir kavramdır.

Gerçek anlam ve anlaşılan anlam birbirinden farklıdır. Gerçek anlam semantik, anlaşılan anlam pragmatik inceleme gerektirir. Anlaşılan anlamı araştırmak için ifade yapısı yanında yorumlamayla da ilgilenmek gerekir. Dilbilimsel anlam ve kavramsal yapı da bir ve aynı şey değildir. Kavramsal yapıda diller arasındaki benzerlikler artar; dilbilimsel anlamda ise dil ve o dilin beslendiği kültürden kaynaklanan farklılıklar olabilir. Anlambilimin ayrı bir mental alanı vardır. Bunun kavramsal yapının alt parçasını oluşturduğu düşünülebilir fakat yalnız kişisel bilgiyi değil paylaşılan bilgiyi 
yansıtan sosyo-kültürel bir yanı da vardır. Gel-ve git- fiilleri bir yerde bulunmayı ifade eden fiillere karşıt bir durum yansitırlar. Bununla birlikte başka sıfatların önünde gelmek gibi bir ifadede gel- fiili 'bulunmak' anlamı taşır. Öneri Üçüncü fikranın sonuna gelmek üzere aşağıdaki cümlenin ifade edilmesi ifadesinde de gel-fiili belli bir yerde yerleşim anlamı taşımaktadır.

5) Kuş ă̆aca doğru uçup gitti

6) Kuş elma ă̆acından armut ă̆acına doğru uçtu

5. cümlede bir yönelimin yanı sıra bir yerde bulunma anlamı da söz konusu olabilir. Kuş hareketi tamamlamış ve son yerinde bulunduğunda "kuş ağaçtadır."

Önce bulunulan yer (konuşanın bulunduğu yer) Hareket (uçmak)

Sonra bulunulan yer (ă̆aç)

6. cümlede ise önce bulunulan yerin konuşanın bulunduğu yer olma zorunluluğu kalkar. Dolayısıyla her iki durumda istem durumlarında da farklılık söz konusudur. Altıncı cümlede seçimli istemin cümlede bulunma zorunluluğuna karşın beşinci cümlede böyle bir durum söz konusu değildir.

- $a$ doğru gibi yönle ilgili ifadeleri açıklamak için uzamla ilgili yakın ve uzak ve şartla ilgili eğer gibi unsurlardan yararlanmak gerekir.

$\mathrm{X}, \mathrm{A}$ 'ya doğru hareket etti.

$\mathrm{X}$ hareketi bir süre aynı yönde sürdürürse A'ya yaklaşacaktır. Öte yandan O konuya gelecek olursak gibi bir ifadede gel- yaklaşma yanında konu değişikliğine de işaret eder.

7) Annesi bir yerlere gitse çok üzülürdü

8) Sen nereye gidiyorsun?

7. cümledeki git- fiili ile 8 numaralı soru cümlesindeki git- fiilinin durum bağlamı farklılık gösterir. 7. cümlede anne ana cümle eyleminin failinden bilinmeyen bir yere doğru hareket etmektedir. Bu cümlede git- eyleminin belirttiği hareket tamamlanmıştır. 8. cümlede ise git- eylemiyle belirtilen hareket henüz başlangıç noktasındadır.

Uzamla ilgili hareket bir varlığın yerindeki zaman içindeki değişimdir. Gel-ve gitfiillerinin açıklanmasında dört bileşen önemlidir: bir yolda hareket eden, kaynak, hedef, çevre.

9) Ali dün Adana'dan Bursa'ya gitti.

9. cümlede bir yolda hareket eden: Ali (X)

Önce bulunulan yer: Adana (kaynak)

Sonra bulunulan yer: Bursa (hedef)

Çevre: Bursa ve Adana arasındaki bölgedir.

Önce bulunulan yer: A

Sonra bulunulan yer: B 
X dün A'daydı. X bugün A'da değil.

$\mathrm{X}$ bugün $\mathrm{B}$ 'de.

Bazı fiiller kimi zaman gel- ve git- fiillerinin anlamını verecek şekilde kullanılabilmektedir. Söz gelişi; Ali eve vardı mı? cümlesinde var- fiili; Ali buradan geçti mi? cümlesinde geç- fiili; Ali, Ankara'ya döndü mü cümlesinde dön-fiili; Uçak, Ankara'ya ulaştı mı? cümlesinde ulaş- fiili, Bugün şehre ineceğim cümlesinde in- fiili, Aşă̆ıya doğru yürü cümlesinde yürü- fiili gel- ve git- fiillerinin anlamını verecek şekilde kullanılmıştır. Bu fiillerin hepsinde bir yer değişikliği, bir seyahat etme eylemi geçerlidir.

Gel- ve git- fiilleri temel anlamlarıla yürümek, uçmak, yüzmek vb. gibi bir hareket gerektirir. Değişik şekillerde gerçekleşebilecek seyahat etme eylemi için araç (kimle; ayakla, atla, arabayla, uçakla, helikopterle, gemiyle, kayıkla, tekneyle vb.) gerekli olabilir de olmayabilir de. Araç kullanımı için önce bulunulan yer ile sonra bulunulan yer arasındaki mesafe ve yer koşulları da önemlidir. Diller sözlüksel anlambilim aşamasında farklılıklar gösterebilir. Goddard (1997: 155-156) Almanca, Lehçe gibi bazı dillerde git- eylemi için ayakla veya araç kullanarak gerçekleştirilmesine bağlı olarak farklı fiiller kullanıldığını (Almancada gehen 'ayakla gitmek' fahren 'araçla gitmek'), İngilizce gibi bazı dillerin böyle bir ayrım yapmadığını belirtir. Türkçe için de böyle bir ayrımın olduğu söylenemez.

Hem gel- hem de git- fiilinin kullanılabildiği bazı bağlamlar da vardır fakat burada çok küçük farklı etkiler söz konusudur.

10) Ben senin odana geldim fakat sen ayrılmıştın

11) Ben senin odana gittim fakat sen ayrılmıştın

Konuşma anında hitap edilenle konuşan kişi oda dışında bir yerdeyse hem 10 hem de 11. cümlenin kurulabilmesi mümkündür.

12) Sinemaya geleceğini annene söyledin mi?

13) Sinemaya gideceğini annene söyledin mi?

12 ve 13. cümlede hedef, konuşmacının da hitap edilenin de konuşma anında bulunmadığ bir yerdir. $\mathrm{Bu}$ ortak hedefe karşılık 12. cümlede gel- fiilinin seçilmesi konuşan kişinin hitap edilen kişiyle birlikte hareket etmesinden kaynaklanır. 13. cümlede ise konuşan ve hitap edilenin ayrı hareketleri söz konusu olduğu için git- fiili tercih edilmiştir.

14)Mezuniyet törenine gelip gelemeyeceğinizi merak ediyorum.

15)Mezuniyet törenine gidip gidemeyeceğinizi merak ediyorum.

14. cümlede gel-, 15. cümlede ise git- fiili tercih edilmiştir. Bu tercih konuşan kişinin konuşma anında veya gönderim zamanında (törenin yapılacağı zaman) varış noktasında olup olmamasıyla ilgilidir. Konuşan kişi konuşma anında veya gönderim zamanında varış noktasında ise gelip gelemeyeceğinizi, varış noktası dışında bir yerdeyse gidip gidemeyeceğinizi yapısı tercih edilir. 
Ben seninle gelebilir miyim? Sen benimle gelmek ister misin? Cümlelerinde gelkonuşmacıya doğru bir hareketi anlatmaz. Konuşmaciyla birlikte belli bir yöne doğru bir hareketi, esasen bulunulan yerden başka bir yere doğru bir hareketi ifade ettiği halde gel- fiili git- fiiline tercih edilebilir.

Ben sana geleceğim cümlesi daha beklendik bir cümle olmakla birlikte Ben sana gidiyorum cümlesi de hitap edilenin her zaman bulunduğu ve konuşmacının söz konusu ettiği mekâna doğru bir harekette kabul edilebilir bir cümle olur.

Gel- fiilinin kullanımında konuşmacıya doğru hareket temel (prototipe ait) anlam, diğer kullanımlar bir başkasının yerine kendini koyma, bir başkasının bakış açısıyla olaya bakma yeterliliğinin sonucudur. Gösterimsel tasarım, konuşmacının uzak uzamzamansal koordinatları öngörme gücü üzerinde açıklanamayan sınırlamalar yaratır. Gösterimsel merkeze bağlı olarak bu fiillerin anlamında metaforik değişiklikler olabilir. 16 ve 17. cümlelerde böyle bir anlamsal değişim söz konusudur. 18. cümlede ise gel-fiili inanç sistemiyle ilgili olarak metonimik bir anlam kazanmış ve öl-fiilinin anlamını yakalamıştır.

16)Artık kavga noktasına gelmek bir an meselesiydi.

17) Çekileceğiz çekileceğiz ki daha güçlü gelmek için.

18)Allahım! Sana geliyorum.

Gel- ve git- fiilleri eşdizimlilerine ve çekim özelliklerine bağlı olarak istem ve anlam değiştirebilir. Bu fiiller anlamsal olarak karmaşık sözcüklerdir. Söz gelişi, rast gelmek 'karşılaşmak' iken rast gele bir kalıp söz olarak özellikle balık tutan insanlara yönelik söylenen ve balık avının bol olmasını temenni eden bir dışavurucu edimsel sözdür.

19) Öykülerinize, öykücülüğ̈̈nüze gelmek istiyorum.

20)Bahar gelmek üzereydi.

19. cümlede bir konu değişikliğine gitmek söz konusu iken 20. cümlede zamanda ve mevsimde bir değişime işaret edilmektedir.

Güncel Türkçe Sözlük’te (e-GTS10.09.2021) gel- fiilinin 36 anlamı sıralanmıştır. Burada büyük ölçüde eşdizimliliğe bağlı anlamlar söz konusudur. Söz gelişi; Eski çağlardan birçok anıt günümüze kadar gelmiştir cümlesinde zamanda harekete bağlı 'varlığını sürdürmek, sağlam kalmak'; Saat 9'a geliyor cümlesinde 'sürenin dolarak belli bir zaman dilimine ulaşmak'; Boyu ancak omzuna geliyor cümlesinde 'kadar olmak'; kötülük/fayda gelme-eşdizimlisinde 'çıkmak, yönelmek, dokunmak' anlamları kazanmıştır. e-GTS'de 15. anlam olarak verilen 'daha önce üzerinde durulmuş olan bir konuya yeniden dönmek’ anlamı Şimdi sözü burada kesip asıl konumuza gelelim örnek cümlesi için doğru olmakla birlikte asıl eşdizimli unsurlar konuya / sadede / meseleye gel- şeklinde belirlenebilir ve buradaki konunun daha önce üzerinde durulmuş olması şart değildir. Bu davranışlardan ne gelir bilinmez cümlesinde 'sonuç çıkarma'; Biraz üşütmeye gelmiyor, hemen hastalanıyor; eleştiriye gelemiyor gibi ifadelerde 'dayanmak, tahammül etmek' anlamları; Dediğime geldin mi? cümlesinde 'doğruluğuna hak vermek' anlamı; iyi / kötü / güzel gel- eşdizimlilerinde 'etki etmek, hissetmek' anlamı; Çiftlikten onlara ayda beş yüz lira gelir cümlesinde 'kazanılmak, 
sağlanmak' anlamı; Bu ayakkabı sana küçük gelir cümlesinde 'uymak' anlamı; Başa gelen çekilir; başa bela gel- ifadelerinde 'maruz kalmak, uğramak' anlamı; Böyle söylemeye gelmez cümlesinde 'uygun düşmek'; tanesi on liraya gel- ifadesinde 'mal olmak' anlamı söz konusudur. Alışageldiğimiz bir anlamı vardı cümlesindeki alışagelbirleşik fiilinin ya da meydana gelmek birleşik fiilinin eşdizimlenme düzeyinin deyimleşmeye doğru geliştiği söylenebilir. e-GTS'de gel- fiili içeren atasözleri, deyimler, birleşik fiiller sıralanırken bazı kalıp sözler de verilmiştir: gel keyfim gel; gel zaman git zaman gibi. e-GTS'de söz konusu fiilin temel anlamı dışında verilen anlamlar eşdizimlenmeye bağlı olarak ortaya çıkmış anlamlardır. Türkçe sözlüğün eşdizimlilik özelliklerini dikkate alarak güncellenmesi yerinde olmuştur. Bununla birlikte sözlüğe gel- fiili içeren bazı başka eşdizimli yapılar da eklenebilir.

Gel- fiilinin eşdizimlendiği bazı başka dil unsurları eşdizimlilik düzeylerine göre aşağıda sıralanmıştır. Bu eşdizimlilerin sayısı arttırılabilir. Dil canlı kaldığı sürece yeni yeni eşdizimli yapıların oluşacağı da bir gerçektir.

Sınırlı eşdizimliler arasında değerlendirilebilecek haber/ mesaj/ mektup vb. gelmek eşdizimlileri öznenin cansız varlık olması gerekliliğiyle sınırlanmıştır.

bir araya/ yan yana/ yüz yüze/ burun buruna/ karşı karşıya vb. gelmek eşdizimlileri farklı öznelerin farklı yönlerden aynı yere hareketini gerektirir.

karşı karşıya gelmek bazı bağlamlarda 'zıtlaşmak' anlamında deyimsi eşdizimli olarak da kullanılabilir. Aileye/ otoriteye/ krala/ başkana/ birinin fikrine, yasaya vb. karşı gelmek eşdizimlilerinde kişi, kurum veya bunlara ait düşünce veya ilke sinırlaması vardir.

Görevel iktidara gelmek; politikada/ işte/ kariyerde belli yerlere gelmek/ belli bir durumal seviyeyel iyi bir konumal düzeyinel halinel daha iyi yerlere gelmek eşdizimlileri soyut bir yer hedefi, durum değişikliği gerektirir; adet/ alışkanlık/ huy haline gelmek de benzer fakat daha soyut bir durum anlatır.

Sonral öncel başta gelmek eşdizimlileri 'üstün durumda olmak, sırada birinci olmak' herhangi bir sirada bulunma gerektirir.

Çişi/ göresi/ yiyesi/ içesi gelmek 'belli bir ihtiyacı duymak, istemek' anlamında olup ihtiyaçlarla sınırlanmıştır.

karşı tarafa sevimsiz/ sevimli/ itici gelmek 'bir duyguyu hissettirmek, bir duyguyu uyandırmak, bir duygu yaratmak' anlamlarına gelen eşdizimli yapılar git- fiilinin bazı eşdizimlileriyle benzerlik gösterir. Söz gelişi git- fiili Hoşa gidecek/gitmeyecek sözler/ davranışlar; zoruna git- gibi bazı eşdizimli yapılarda uzamsal bir hareket veya pozisyonu karşılamaz; 'kişide belli bir duygu yaratmak' anlamını verir. Bu eşdizimli yapılarda hem gel- hem de git- fiili GELMEK fiilleri (GO verbs) sınıfından çıkıp OLMAK fiilleri (BE verbs) sınıfına geçmektedir.

duymazllktan/ görmezlikten/ görmezden/ işitmezlikten/ bilmezden/ bilmezlikten gelmek 'farkında değilmiş gibi davranmak' eşdizimlileri duyu fiili tabanında şekillenmiş bir adla sınırlıdır ve $+\mathrm{dAn}$ morfolojik istemini gerektirir. 
kendine gelmek 'bilinçsiz durumdan bilinçli hale gelmek'; uygun gelmek 'uymak, yakışmak, elverişli olmak'; doğal gelmek 'doğal bulmak', duru gelmek 'duru bulmak'; eceli gelmek 'ölümü ya da yok olması kaçınılmaz duruma gelmek'; oyuna gelmek 'kandırılmak'; kökenden/ iyi bir aileden gelmek 'kaynaklanmak, türemek'; gündeme gelmek 'söz konusu edilmek, üzerinde konuşulmak'; konuya/ sadede gelmek 'boş konulardan uzaklaşıp temel meseleyi anlatmak'; süre gelmek 'geçmişte başlayıp şu anda da devam etmek'; ayağına/ huzuruna gelmek 'alçakgönüllülük göstererek birinin yanına gelmek' anlamlarında sınırlı eşdizimli yapılar iken ayağına gelmek 'emek vermeden elde edilmek' anlamında deyimsi eşdizimlidir.

Anlam/ın/a/ manaya/ manasına gelmek 'anlam bildirmek'; galip/ mağlup gelmek 'yenmek'; denk/ rast gelmek 'uygun gelmek, karşılaşmak'; sonu gelmek 'yok olmaya yaklaşmak'; garip/ tuhaf/ acayip gelmek 'tuhaf bulmak, garipsemek' gibi başka sinırlı eşdizimliler de vardır.

Deyimsi eşdizimliler; anlam değişiminin birleşim koşullarına bağlı olarak her iki birleşen unsurda da betili bir anlam bulunan fakat birleşenlerin anlamlarından yola çıkılarak birleşim anlamlarına ulaşılabilen eşdizimlilerdir: burama/sına gel'tahammülün zorlanması, tepki vermeye az kalmak'; başına gelmek 'uğramak, maruz kalmak'; dünyaya gelmek 'doğmak'; dile gelmek 'konuşmaya başlamak'; dize gelmek 'yenilgiyi kabul etmek, otoriteye boyun eğmek'; yola gelmek 'istendik bir durum almak, bir durumu kabullenmek'; meydana gelmek 'oluşmak'; nazara/ göze gelmek 'maruz kalmak, uğramak'; gibi/me/sine/ne gelmek 'gibi görünmek, ...sanısını uyandırmak" gibi.

Deyimler: üstesinden gelmek 'başarmak'; yüreği ă̆zına gelmek 'çok korkmak' gibi.

Gel- fiili bazı sözcüklerle birleşerek birleşik yapıda isim, zarf ve bağlaç da teşkil etmiştir; tümdengelim, gelip geçici, gide gele, rastgele, söz gelimi, gelgelelim gibi. GTS'de gel- fiiliyle teşkil edilen bu birleşik sözcükler yer alırken gelgit 'med-cezir', gelberi 'yüksek dallardaki meyveleri toplamak için kullanılan çatallı sopa' gibi bazı birleşik sözcüklere yer verilmemiştir (e-GTS 16.09.2021).

Bunlar dışında Hoş geldiniz gibi kalıp sözler içinde de gel- fiilini görmek mümkündür.

GTS'de git- fiilinin 22 anlamı sıralanmıştır (e-GTS 16.09.2021). git- fiili; Bu renk ona gitmedi cümlesinde 'yakışmadı' anlamında; Maaşlar ev kirasına gidiyor cümlesinde 'harcanmak' anlamında; Bu böyle nereye kadar gider cümlesinde 'devam etmek' anlamında; İki ton kömür üç ay gider cümlesinde 'yeter, yetişir' anlamında, Bu giysi iki yıl gider cümlesinde 'dayanmak' anlamında; Yaz gitti, kış geldi cümlesinde 'zamanın geçmesi' anlamındadır. Bu anlam için GTS'deki nesnesiz açıklaması yeterli değildir, anlamı belirleyici olan sözdiziminde özne konumundaki unsurun zamanla ilgili bir sözcük olmasıdır. Gemiler ve saray hepsi gitti cümlesinde cansız bir varlık söz konusu olduğu için 'yok olmak'; Ben giderim adım kalır cümlesinde canlı bir varlık söz konusu olduğu için 'ölmek' anlamında; Mahkemeyel temyize gitmek ifadesinde metonimik olarak 'başvurmak' anlamında; para ayarlamasına/ düzenlemeye/ kanun değişikliğine gitmek ifadelerinde 'yapmak' anlamında sınırlı eşdizimli yapılar söz konusudur. 
GTS'de 19. anlam -den satılmak Altın kaçtan gidiyor? örneğiyle verilmiştir (e-GTS 16.09.2021). Bu anlam -den morfolojik istemiyle sinırlanamaz, $+(\mathrm{y}) \mathrm{A}$ morfolojik istemiyle de bu anlam oluşabilir: kaça/ ucuza/ pahalıya/ beş paraya git- gibi sınırlı eşdizimli yapılarda 'el değiştirmek, verilmek, satılmak' anlamları söz konusudur.

Git- fiili; gözünün feri/ duvarın boyası git-deyimsi eşdizimli yapısında 'bir şeyin zarar görmüş olması' anlamındadır. Git- fiiliyle oluşan diğer deyimsi eşdizimli yapılar şöyle sıralanabilir; kafasının dikine git- 'hiçbir öğüde uygun davranmayıp istediğini yapmak' (bu yapıda kafa sözcüğ̈̈ metonimik anlamda bütün bedeni temsil edecek şekilde kullanılmıştır.); zoruna git- 'bir söz, bir davranış vb. nedeniyle gücenmek, onuruna dokunmak' anlamında; garib/ine/imel tuhaf/ına/ımal acayib/ine/ime git'yadırgamak, tuhaf bulmak, tuhaf saymak, öyle değerlendirmek' anlamında; boşa gitmek 'hiçbir işe yaramamak' anlamında; aklı başından gitmek 'bilincini yitirmek, ne yapacağını bilemez olmak' anlamındadır. Ülke elli yll geriye gitti cümlesinde mecazi anlamdaki geri bir yönelim metaforudur ve bu birleşik içinde git- fiili 'durum değişikliği’ anlamı vermektedir. Böyle gelip böyle git- ifadesi değişimin olmamasına işaret eder. Bu birleşik içinde kazandığ 1 anlamla bir hareket fiili olan git- fiili durgun hale gelmiş, GİTME fiilleri sınıfından çıkarak KALMA fiilleri grubuna girmiştir. Başını alıp gitmek eşdizimlisi 'kimseye danışmadan veya haber vermeden bulunduğu yerden ayrılmak' (burada baş metonimik) anlamında; hoşa gitmek 'iyi, güzel bulunmak, beğenilmek' anlamlarında sınırlı eşdizimli yapılardır. Git- fiiliyle kullanımlar iyelik eki kullanımını gerektirirken gel- fiiliyle bu gereksinim ortadan kalkar: Bu durum bana tuhaf geliyor örneğindeki gibi. Yine Bu işin sonu nereye gidiyor cümlesinde eşdizimlenmeye bağlı olarak 'bir sonuca, duruma ulaşmak, varmak' anlamı oluşmuştur.

Git- fiili birleşik yapıda sıfat ve zarflar da teşkil etmiştir: gitmeli gelmeli bir sürü araç; gide gele, gitgide gibi.

\section{Sonuç}

Aynı kökten gelen ve iki üyeli ilişki grubu oluşturan gel-ve git- fiilleri, temel anlamları dikkate alındığında çift yönlü hareket fiilleri olup yer değişimini betimleyen fiillerdir. Gel- fiili git- fiiline göre daha gösterimsel bir fiil olup kullanımında konuşmacıya doğru hareket temel (prototipe ait) anlam, diğer kullanımlar genellikle bir başkasının yerine kendini koyma, bir başkasının bakış açısıyla olaya bakma yeterliliğinin sonucudur. Eşdizimlenmeye ve gösterimsel merkeze bağlı olarak gelfiilinin de git- fiilinin de anlamında betili (figüratif) değişiklikler olabilmektedir. Gelve git- fiilleri temel anlamlarıyla uzamsal pozisyon gösteren hareket fiilleri olup GITME fiilleri (GO verbs) olarak adlandırılan bir grup içinde yer alsa da eşdizimlenmeye, aldıkları eklere, çekim özelliklerine bağlı olarak KALMA filleri (STAY verbs) ve nadir de olsa OLMA fiilleri (BE verbs) grubuna geçebilmektedir. 


\section{Kaynakça}

CAFEROĞLU, Ahmet (1968).Eski Uygur Türkçesi Sözlüğü, İstanbul: TDK

Clauson, Sir Gerard (1972). An Etymological Dictionary of Pre-Thirteenth Century Turkish, Oxford: Oxford University.

DANKofF, Robert; Kelly, James (1982-1985). Mahmud al-Kaşgari Compendium of the Turkic Dialects 1-3, Washington: Harvard University.

DiNAR, Talat (2016). "Türkçede Bir Deyimleşme Örneği: Gibime gelmek”. Türkbilig, 2016/31: 145152.

e-GTS = TÜRK Dil KURUMU (2021). Güncel Türkçe Sözlük. https://sozluk.gov.tr/ (Erişim Tarihi: 18.09.2021)

e-TUD = (2021) Türkçe Ulusal Derlem. https://v3.tnc.org.tr (Erişim Tarihi: 16.08.2021)

GatherCole, Virginia C. (1977). "A study of the comings and goings of the speakers of four languages: Spanish, Japanese, English, and Turkish.” Kansas Working Papers in Linguistics, 2: 61-94.

GodDard, Cliff (1997). "The semantics of coming and going”. Pragmatics, 7/2: 147-162.

GüLENSOY, Tuncer (2018). Türkiye Türkçesindeki Türkçe Sözcüklerin Köken Bilgisi Sözlügüu. İstanbul: Bilge Kültür Sanat.

JACKENDOFF, Ray (1987). Consciousness and the Computational Mind, Cambridge. MA: MIT.

ÖNCÜL, Vildan (2020). 6-36 Aylık Çocuklarda Türkçenin Gelişsimi. Doktora Tezi. Samsun: 19 Mayıs Üniversitesi.

PARLAK, Hüseyin (2016). "Rusçadaki Hareket Fiillerinin Ana Dili Türkçe Olan Sınıflarda Öğretilmesinin Sorunları, Prensipleri ve Yöntemleri". İdil, 5/20: 33-42.

StEEN, Francis Frode (1996). Communication Studies. Los Angeles: University of California.

TEKin, Talât (1988). Orhon Yazttlart. Ankara: TDK.

TeKin, Talât (2015). Irk Bitig. Ankara: TDK.

WiLKINS, David P. and Deborah HILl (2020) "When "go" means "come": Questioning the basicness of basic motion verbs". Cognitive Linguistics, 6-2/3: 209-259. 